Review

\title{
The Power of Phytochemicals Combination in Cancer Chemoprevention
}

\author{
Balsam Rizeq ${ }^{1,2}$, Ishita Gupta ${ }^{3}$, Josephine Ilesanmi ${ }^{1}$, Mohammed AlSafran¹, MD Mizanur Rahman¹, Allal \\ Ouhtit ${ }^{\circledR}$
}

1. Department of Biological and Environmental Sciences, College of Arts and Sciences, Qatar University, Doha, Qatar

2. Biomedical Research Center, Qatar University, Doha, Qatar

3. College of Medicine, Qatar University, Doha, Qatar

$\triangle$ Corresponding author: Prof. Allal Ouhtit, Department of Biological and Environmental Sciences, College of Arts and Sciences, Qatar University, Doha, Qatar. Tel: (+974)-4403-7572; Fax: (+974)-4403-4531; E-mail: aouhtit@qu.edu.qa

(c) The author(s). This is an open access article distributed under the terms of the Creative Commons Attribution License (https://creativecommons.org/licenses/by/4.0/). See http://ivyspring.com/terms for full terms and conditions.

Received: 2019.02.24; Accepted: 2019.12.03; Published: 2020.05.18

\begin{abstract}
Conventional therapies for cancer treatment have posed many challenges, including toxicity, multidrug resistance and economic expenses. In contrast, complementary alternative medicine (CAM), employing phytochemicals have recently received increased attention owing to their capability to modulate a myriad of molecular mechanisms with a less toxic effect. Increasing evidence from preclinical and clinical studies suggest that phytochemicals can favorably modulate several signaling pathways involved in cancer development and progression. Combinations of phytochemicals promote cell death, inhibit cell proliferation and invasion, sensitize cancerous cells, and boost the immune system, thus making them striking alternatives in cancer therapy. We previously investigated the effect of six phytochemicals (Indol-3-Carbinol, Resveratrol, C-phycocyanin, Isoflavone, Curcumin and Quercetin), at their bioavailable levels on breast cancer cell lines and were compared to primary cell lines over a period of 6 days. This study showed the compounds had a synergestic effect in inhibiting cell proliferation, reducing cellular migration and invasion, inducing both cell cycle arrest and apoptosis. Despite the vast number of basic science and preclinical cancer studies involving phytochemicals, the number of CAM clinical trials in cancer treatment still remains nascent. In this review, we summarize findings from preclinical and clinical studies, including our work involving use of phytochemicals, individually as well as in combination and further discuss the potential of these phytochemicals to pave way to integrate CAM in primary health care.
\end{abstract}

Key words: Complementary alternative medicine, Cancer, Phytochemical combination, Genomics, Review

\section{Introduction}

Health challenges pose major burdens on population economic standards, life expectancy and mortality rate. Cancer is a major contributor to these global pressures with epidemiological evidence presenting a record of more than 14 million new cases and a mortality rate of approximately 8 million every year [1]. The rise in mortality rates is associated with increase in tumor recurrence due to cells becoming resistant to chemo- or radio-therapy [2]. Therefore, it is critical to develop an effective alternative strategy to manage and treat cancer is imminent.

Some bioactive molecules have been isolated, characterized and identified as phytochemicals. These phytochemicals are classified based on their chemical composition and structure to carotenoids, organosulfur compounds, and phenolics. Accumulating evidence shows that many of these phytochemicals can target a wide variety of signalling molecules implicated in cellular growth, proliferation, differentiation, and death in a series of cell types [3-6]. With an increase in cancer incidence and high mortality rates, a profound understanding of dietary combinations as potential chemo-preventive agents is undoubtedly an attractive strategy to combat cancer and promote global health.

In this review, we will focus on several bioactive phytochemicals as well as their target effectors in cancer. 


\section{Conventional Medicine and Treatment of Cancer}

The variations in treatment response suggest intrinsic or acquired therapeutic resistance exists in a subset of cancer patients. This frequently leads to treatment failures, disease progression, and often mortality. Cancer can be treated with both invasive and non-invasive treatment modalities such as surgery, chemotherapy, radiation therapy, as well as other therapeutic modalities including gene therapy, immunotherapy, hormone therapy, photo-dynamic therapy, targeted therapy, palliative care, and a combination of these (e.g. radiosurgery) [7]. While, chemotherapy and radiotherapy remain the major standard care for cancer patients as it helps to shrink tumor size and kill cancer cells at the primary sites or metastasizing sites [8], the response to treatment varies substantially in different types of cancer, or even among patients with the same type of cancer. Among the conventional procedures, radiation therapy or radiotherapy is one of the most common treatments for cancer [9]. Traditional radiotherapy uses high energy electromagnetic waves, (e.g. gamma rays and X-rays) to destroy and kill tumor cells by damaging their DNA [10]. Furthermore, radioimmunotherapy studies in rodent cancer models using radiolabeled derivatives of J591 with a-emitters elicits anti-proliferative potential with minimal damage to the surrounding normal cells $[11,12]$.

An ideal chemotherapeutic anticancer agent would selectively kill tumor cells but not normal cells. However, most conventional anticancer drugs display non-specificity, causing many undesired toxic effects and patient discomfort [13]. In fact, because of the ineffectiveness of current drugs, previous studies have proposed a model where an understanding of the mechanisms underlying tumor-host interactions might lead to the discovery of new drugs that can overcome the resistance issues [14]. In addition to pure chemotherapy, specific chemical agents (radio-sensitizers), can generally enhance the cell's response to ionizing radiation as well as promote both direct and indirect effects of radiation [15]. Consequently, the development of agents that are capable of selective accumulation in solid tumors represents an exciting new field and forms a key goal of modern anticancer research.

Many targeted therapies, including monoclonal antibodies and pro-inflammatory cytokines, have been developed to target key pathways in tumorigenesis. For instance, interleukin-2 (IL-2) plays an essential role in the immune response by stimulating proliferation of T-cells as well as inducing the generation of cytotoxic T lymphocytes (CTLs) and natural killer (NK) cells; which in turn attack tumor cells. However, despite all these immunity-boosting effects, administration of IL2 in therapeutically active doses is still hampered by excessive toxicities [16]. Moreover, as an adjuvant cancer current treatment modality is based on the cytotoxic properties of localized high temperatures $\left(43^{\circ} \mathrm{C}\right)$ or hyperthermia that is achieved within cancer cells and tissues, the renaissance of this method is mainly based on the modern electromagnetic heating techniques and is usually achieved by using microwaves to heat the tumor $[17,18]$.

\section{Shortcomings of conventional therapy}

Despite its effectiveness, conventional chemotherapy has many side effects. For instance, cutaneous hypersensitivity reactions are observed in patients receiving treatments based on platinum alkylating agents, topoisomerase and mitotic inhibitors; Hyperpigmentation is prevalent with the use of alkylating agents such as ifosfamide, cyclophosphamide, and thiotepa. Hand and foot syndrome is prevalent in liposomal doxorubicin, daunorubicine and 5'-fluorouracil [19].

The development of biopharmaceuticals as an alternative hybrid therapy also poses limitations. Biologicals are complex anticancer macromolecules such as monoclonal antibodies, antibody fragments and anti-body-drug conjugates. These therapies have clinically displayed low efficacy and weak ability to penetrate solid tumors. Other therapies such as drug delivery systems (DDS) are designed with conventional active drugs molecules attached to biological carriers such as liposomes, nanoparticles or biodegradable polymers [20]. It has been reported that molecular target therapies like DDS are linked with ophthalmologic toxicities ranging from blurred vision, conjunctivitis, keratitis, and optical neuritis [21].

One of the major disadvantages of conventional therapies is the recurrence, as not all cancer stem cells are eradicated from the body. In addition, the development of multi-drug resistance (MDR) is a significant clinical challenge. Also, in many countries, social and economic burdens incurred through treatment costs remain among the many hurdles to be overcome for a global reduction in cancer incidence and mortality. Therefore, there is a pressing need to identify novel approaches and therapies that may offer relatively cost-effective regimens with less undesired side effects [22]. Many of these complementary and alternative therapies either chemo-preventive or chemotherapeutic are largely inspired by nature, particularly phytochemicals from plants. 


\section{Complementary and Alternative Medicine (CAM) and Role in Cancer Treatment}

Complementary and alternative medicine (CAM) involves approaches and compounds that are not classically considered as conventional therapies [23]. Indeed, CAM represents the use of naturally occurring or synthetic derivatives of dietary phytochemicals for the treatment and prevention of cancer. CAM encompasses a wide range of therapeutic approaches, including herbal medicines, homoeopathic remedies, and essential oil and dietary supplements. Epidemiological and preclinical studies have identified that both nutritional and behavioural factors may significantly affect the prevalence of some cancers. This has led to increased interest in dietary phytochemicals [24]. Contextually, nearly half of cancers diagnosed in the Western world are breast cancers [25]. Importantly, this type of cancer is preventable through health diets rich in plant-based products [26, 27]. Many dietary phytochemicals are naturally occurring bioactive chemicals that can be efficacious in cancer chemoprevention either independently or in combinations [28].

Most phytochemicals are required in high doses to be effective; these doses are often not achievable through diet alone. In general, all types of cancer cells exhibit aberrant gene expression due to mutations in the epigenome because of epigenetic modifications involved in cell proliferation, differentiation and survival [29]. Hence, the epigenetic diet was introduced as a chemo-preventive approach related to delineating the efficacy of dietary bioactive compounds and their effect on modulating the epigenome [29].

Nutrigenomics, another promising cancer chemo-preventive strategy, involves the modulation of gene expression in response to dietary compounds. Therefore, a holistic and intuitive approach for chemo-preventive therapy will make use of these bioactive dietary compounds to regulate epigenomic changes and prevention [30]. Specifically, realistic approaches focus more on the combinational efficacy of these promising dietary phytochemicals.

\section{Chemopreventive dietary phytochemicals}

Chemopreventive dietary phytochemicals are naturally occurring bioactives found in fruits, vegetables, plants, and spices. They possess anti-inflammatory, anti-oxidative, anti-proliferative and pro-apoptotic properties, and are particularly known to inhibit the growth of various cancer cells. Indeed, a steady inverse effect of increased vegetable and fruit consumption with reduced incidence of oral cancer has been reported [31, 32]. Furthermore, dietary phytochemicals have both chemotherapeutic and chemosensitizing effects [33].

\section{Potential Therapeutic Strategies for Dietary Phytochemicals}

Through drug-interaction, the pharmacological effects of dietary phytochemicals demonstrate a positive interaction promoting potency of the bioactive compound via molecular interaction with adjuvant substance (potentiation). They exhibit a combined efficacy which is equivalent to the sum of individual effects (additive), or combined efficacy, which is greater than the sum of individual effects (synergistic), and lastly the combined efficacy which is less than the sum of individual effects $[34,35]$.

\section{Potent dietary phytochemical combinations}

Several epidemiological and case studies have identified the molecular activities of selected phytochemicals that target oncogenic pathways and exhibit chemotherapeutic and/or chemosensitizing effects on cancer cells (Table 1). One area of particular research interest is the identification of the active compounds present in various herbal and dietary interventions and their analysis for anti-cancer properties. For example, polyphenols from green tea, grape seed/skin, anthocyanin and pigments from many flowers, algae, fruits and vegetables are a few of the compounds that have been tested in cancer [36]. Tea, the second most consumed beverage in the world, contains polyphenols shown to possess photo-protective effects from UV induced DNA damages causing oxidative stress, inflammation, changes in cell signalling pathways, and epigenetic alterations. There are three major teas based on fermentation process: black, green and oolong [37]. The most popular tea polyphenols are the green tea phenols with Epigallocatchin-3-gallate (EGCG), the most abundant (50-88\%) component present in green tea [37]. A mice model study found that EGCG promotes the repair of UV-induced cyclobutane pyrimidine dimers (CTDs), a chemical directly responsible for DNA damage [38]. EGCG also prevents inflammation by reducing cyclooxygenase (COX-2) enzyme, a limiting enzyme for a cascade of carcinogenic pathways promoting skin cancer [38]. Recent evidence also indicates that EGCG favorably induced epigenetic changes by modifying miRNA expression in prostate cancer, leading to inhibition of prostate carcinogenesis [39]; indicating EGCG's potent antioxidant capacity [40]. Recently, EGCG along with curcumin (discussed below) showed 
potent inhibitory effects against colorectal carcinoma [41]. Interestingly, along with its long-term safety, as well as its very negligible side-effects, EGCG makes an attractive bioactive in cancer prevention and treatment [42].

A common property of these majority compounds is their anti-oxidant/free radical eliminating ability. However, few of them infuse high free radical formation to result in the killing/elimination of cancer cells. While several research has analyzed effects of individual compounds derived from grape seeds/skin, tea polyphenols, etc., few research studies determined the combined effects of these compounds when used in synergistic, additive or antagonistic combinations. Most studies have evaluated the effects of individual compounds on a variety of cancer cells in vitro. A main draw-back of these studies is the concentration of compounds used typically exceeds their 'bioavailable' concentration: the serum levels achieved by oral intake of extracts (as practiced in CAM) are much less than used in in vitro studies.

\section{Curcumin}

Curcumin, the derivative of turmeric is extracted from the roots of the Curcuma Longa plant. Howells et al [43] determined several bioactivities of this compound. It downregulates cyclin D1, cyclin E, MDM2 and enhances tumor suppressors p21, p27 and p53 [44] leading to arrest of cell cycle, inhibition of proliferation, and induction of apoptosis of a number of cancer cell lines [45]. Furthermore, Yan et al. identified several putative novel molecular targets of curcumin using gene expression profiling [46]. Bioavailability of curcumin seems to be low and plasma levels in nanomolar to micromolar range have been detected after oral administration of this compound [43,47]. The general consensus is that in vitro studies with curcumin in the $10 \mu \mathrm{M}$ range or below might have human physiological relevance. Its role as a chemopreventive agent may lie primarily within the gastrointestinal tract where its concentration is not dependent upon systemic absorption. In spite of low bioavailability, several animal studies have demonstrated the anticancer activity of curcumin in cervical [48], breast [49], prostate [50], liver [51], and lung [52, 53] cancers. Curcumin has been demonstrated to synergize with different agents such as genestin in breast cancer [54], with epigallocatechin-3-gallate in oral cancer [55], with tumor necrosis factor (TNF)- related apoptosis-inducing ligand (TRAIL) on LNCaP prostate cancer cells [56]. Curcumin inhibits tumor cell growth and promotes apoptosis via modulation of specific carcinogenic biomarkers such as cyclooxygenase-2 (COX-2), nuclear factor kappa (NF-kB), tumor necrosis factor alpha (TNF-a), cyclin D1 and STAT-3 $[57,58]$. In cervical cancer, treatment of Siha cells with curcumin showed a profound decrease in EMT via a Pirin-dependent mechanism [48]. On the other hand, in non-small cell lung cancer, curcumin showed regulate EGFR and TLR4/MyD88 pathways in combination to downregulate downstream cell cycle- and EMT-related regulators so as to inhibit cell proliferation and metastasis [53].

Table 1. The different phytochemicals and their corresponding molecular targets underpinning effects on tumor growth, differentiation, proliferation, invasion and metastasis, drug resistance, immune surveillance, inflammation and tumor cell metastasis via different pathways.

\begin{tabular}{|c|c|c|}
\hline Source & Active Ingredient & Literature \\
\hline Broccoli & $\begin{array}{l}\text {-Indole-3-Carbinol } \\
\text { (I3C) }\end{array}$ & $\begin{array}{l}\text { I3C induces apoptosis, antiangiogenic activities and growth inhibition in multiples cancer cell lines and tumours [124, 140]. } \\
\text { I3C induces G1 cell cycle arrest [141]. } \\
\text { I3C inihbits Akt [142]. } \\
\text { I3C inhibits activation of transcription factors including nuclear factor-kappa B, SP1, estrogen receptor, androgen receptor and } \\
\text { nuclear factor-E2-related factor } 2 \text { (Nrf2) [127]. } \\
\text { I3C has broad spectrum of activities, combined with low toxicity [137]. } \\
\text { I3C up-regulated the tumor suppressor protein p23 and down-regulated cell cycle check protein pRb and survival indicator } \\
\text { Survivin [122, 129]. }\end{array}$ \\
\hline $\begin{array}{l}\text { Grape skin and } \\
\text { seeds }\end{array}$ & Resveratrol (RE) & $\begin{array}{l}\text { RE interferes with AKT activity and triggers apoptosis [143]. } \\
\text { RE enhances p53 acetylation and apoptosis [144]. } \\
\text { RE causes G1 arrest [145]. } \\
\text { RE induces apoptosis by TRAIL sensitization [146] and down regulates survivin expression [122]. } \\
\text { Resveratrol blocks proliferation, migration and invasion via NEAT1-mediated Wnt/ } \beta \text {-catenin signaling pathway [147]. }\end{array}$ \\
\hline Tea & $\begin{array}{l}\text { Epigallo-Catechin } \\
\text { Gallate (ECG) }\end{array}$ & $\begin{array}{l}\text { ECG inhibits and Hsp70 and Hsp90 functions [148, 149]. } \\
\text { ECG inhibits hypoxia and serum induced HIF-1 alpha protein accumulation and VEGF expression [150, 151]. } \\
\text { Combination studies have shown that ECG can enhance responses induced by curcumin on breast cancer cells [152]. }\end{array}$ \\
\hline Spirulina & Phycocyanin (P) & $\begin{array}{l}\text { P inhibits cell proliferation and induces apoptosis due to the MAPK, Akt/mTOR/p70S6K and NF-kB pathways [153]. } \\
\text { P inhibits MDR1 through reactive oxygen species and cyclooxygenase-2 mediated pathways [154]. } \\
\text { Potent dietary phyto-antioxidant, anti-inflammatory and anti-cancerous [82] }\end{array}$ \\
\hline Turmeric roots & Curcumin (CUR) & $\begin{array}{l}\text { CUR has anti-proliferative effect [83] and reduces EMT [48]. } \\
\text { CUR induces apoptosis by blocing the PI3K/AKT Pathway [155]. } \\
\text { CUR down regulates cyclin D1, cyclin E, MDM2 and up regulates tumor suppressors p21, p27 and p53 [156, 157]. }\end{array}$ \\
\hline $\begin{array}{l}\text { Stamens of } \\
\text { Saffron }\end{array}$ & Crocin $(\mathrm{Cr})$ & $\begin{array}{l}\text { Saffron inhibits DMBA-induced skin carcinoma [158]. } \\
\text { Saffron causes cell death through apoptosis [159]. } \\
\text { Animal and in vitro studies indicate that saffron and its main constituents such as crocusatin H, crocin-1 and crocin-3 possess } \\
\text { anticancer and anti-tumour activities [160]. }\end{array}$ \\
\hline
\end{tabular}


Recent evidence shows that curcumin targets stem cells of pancreatic cancer [59] as well as reduces inflammation during acute pancreatitis via the mitogen-activated protein kinase-signaling pathway [60]. It has been shown to synergize with other established chemotherapeutic agents such as Oxaliplatin in colorectal cancer cell lines [43], placitaxil in bladder cancer [61], and gemictbine in an orthotopic model of pancreatic cancer. A combination of curcumin and quercetin (a type of Flavonoid) (400/20 mg) was administered to five patients with familial adenomatous polyposis (FAP) and all 5 patients showed reduced polyp size after a period of 6 months dosing compared to the control group [62]. Interestingly, a recent report shows that in combination with metformin, curcumin elicits a potent chemo-preventive effect against oral squamous cell carcinoma through a cancer stem cell-driven mechanism [63]. Kong et al. showed efficacy of dietary curcumin (used at $2 \%$ dose) or a combination of curcumin $(1 \%)$ and PEITC to inhibit high grade carcinoma and increase apoptosis in a transgenic adenocarcinoma of the mouse prostate model accompanied by downregulating the Akt signaling pathway [64]. A number of studies have been reported on the effects of curcumin in ovarian cancer [65]. Cell cycle inhibition, apoptosis induction, inhibition of ovarian cancer tumor growth by $50 \%$, and angiogenesis in vivo (at $500 \mathrm{mg} / \mathrm{kg}$ dose), have been reported as a result of curcumin treatment [65]. Inhibition of NF-KappaB pathway, modulation of Akt and p38 MAPK for induction of G2/M arrest/apoptosis [66], enhancement of Apo2L/TRAIL induced apoptosis [67], modulation of drug metabolizing enzymes [68] were demonstrated. In mice models with HER-2 positive breast cancer, curcumin was found to slow tumor formation [69].

\section{Resveratrol}

Resveratrol, a phytoalexin extracted from grapes, red wine, peanuts and berries with highest concentrations is found in Japanese knotweed (Polygonum cuspidatum) is a powerful antioxidant. Resveratrol is sometimes used therapeutically for treating inflammation and bacterial infections. It has Cox-1 inhibitory activity [70, 71], causes G1 arrest [72], induces apoptosis by TRAIL sensitization and down regulates survivin expression [73]. It has been shown to possess vasorelaxing, anti-inflammatory, antilipidemic, anti-estrogenic, antioxidant, anti-fungal and antibacterial properities [74-76]. In-vitro investigations demonstrated its anticancer potential in a wide variety of tissues including breast, colon, pancreas, stomach, prostate, head and neck, ovary,

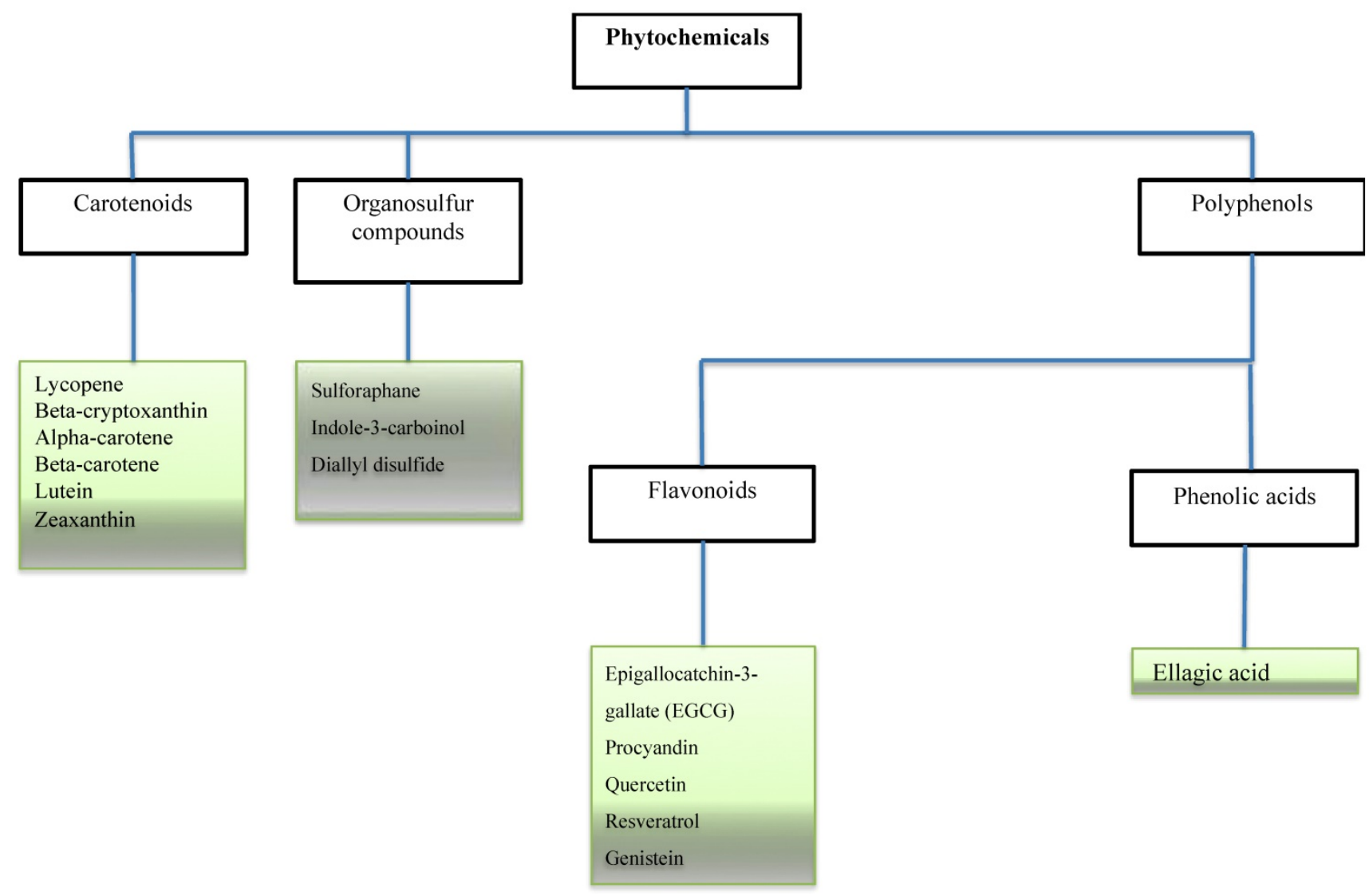

Figure 1. Phytochemicals in cancer related studies. The Figure illustrates the most studied phytochemicals that can inhibit tumor growth and progression. 
liver, lung, and cervix [74]. It has a wide variety effects on a number of cancer cell lines including LNCaP (prostate), MCF7, T47D, MDA-MB231 (breast), and melanoma [77].

Several research of resveratrol effects on ovarian, breast and prostate cancers were analyzed [78-83]. It was shown to inhibit Hypoxia induced Factor-1 alpha and VEGF expression in ovarian cancer cells and was associated with inactivation of $\mathrm{p} 42 / \mathrm{p} 44$ MAPK, p70S6K, and enhanced degradation of HIF-1 alpha protein [81]. Glucose metabolism was blocked leading to autophagy $[79,80]$ in a panel of five ovarian carcinoma cell lines when synergized with cisplatin and doxorubicin [84]. Microarray analysis of gene expression profile revealed modulation of 118 genes by more than 2 fold after $50 \mu \mathrm{M}$ RE treatment of PA-1 ovarian cancer cells [71]. One of the most highly up-regulated genes was NADPH quinine oxidoreductase 1, which has been shown to be involved in p53 regulation.

Recent work has shown that resveratrol synergizes with vitamin E analog alpha-TEA and methylseleninic acid to inhibit breast cancer cell growth [78]. Recent reviews of this compound emphasize its ability to target multiple cellular pathways involved in metabolic syndrome, aging, cardiovascular diseases and cancers $[82,83]$. In-vivo investigations of Harper et al [78] demonstrated that resveratrol fed in the diet (at $625 \mathrm{mg} / \mathrm{kg}$ dose) to Transgenic Adenocarcinoma Mouse Prostate (TRAMP) model reduced the incidence of poorly differentiated prostatic adenocarcinoma by 7.7 fold. This decrease was accompanied by more than $50 \%$ decrease in prostate cell proliferation, IGF-1 levels and its downstream effectors- phosphor ERKs 1 \& 2 in the prostate [78]. The inhibition of carcinogenic pathways was noted in a study showing that administration of 1 gram of resveratrol daily for 4 weeks significantly inhibited plasma cytochrome p450 enzymes such as 2D6, 2C9, CYP1A2 and CYP3A4 compared to baseline [85]. Resveratrol also promotes immune-surveillance by modulating natural killer (NK) cells by eliminating spontaneous tumor cells. Clinical studies showed a correlation between administration of 1 gram resveratrol per day and increased expression of NKG2D antigen receptors on NK cells in the blood [86]. Recently, it was shown that resveratrol acts as an epigenetic regulator owing to its ability to alter DNA methylation and miRNA expression $[87,88]$. Its role in inhibiting colorectal cell invasion as well as in attenuating angiogenic responses and suppressing tumor metastasis has also been reported $[89,90]$.

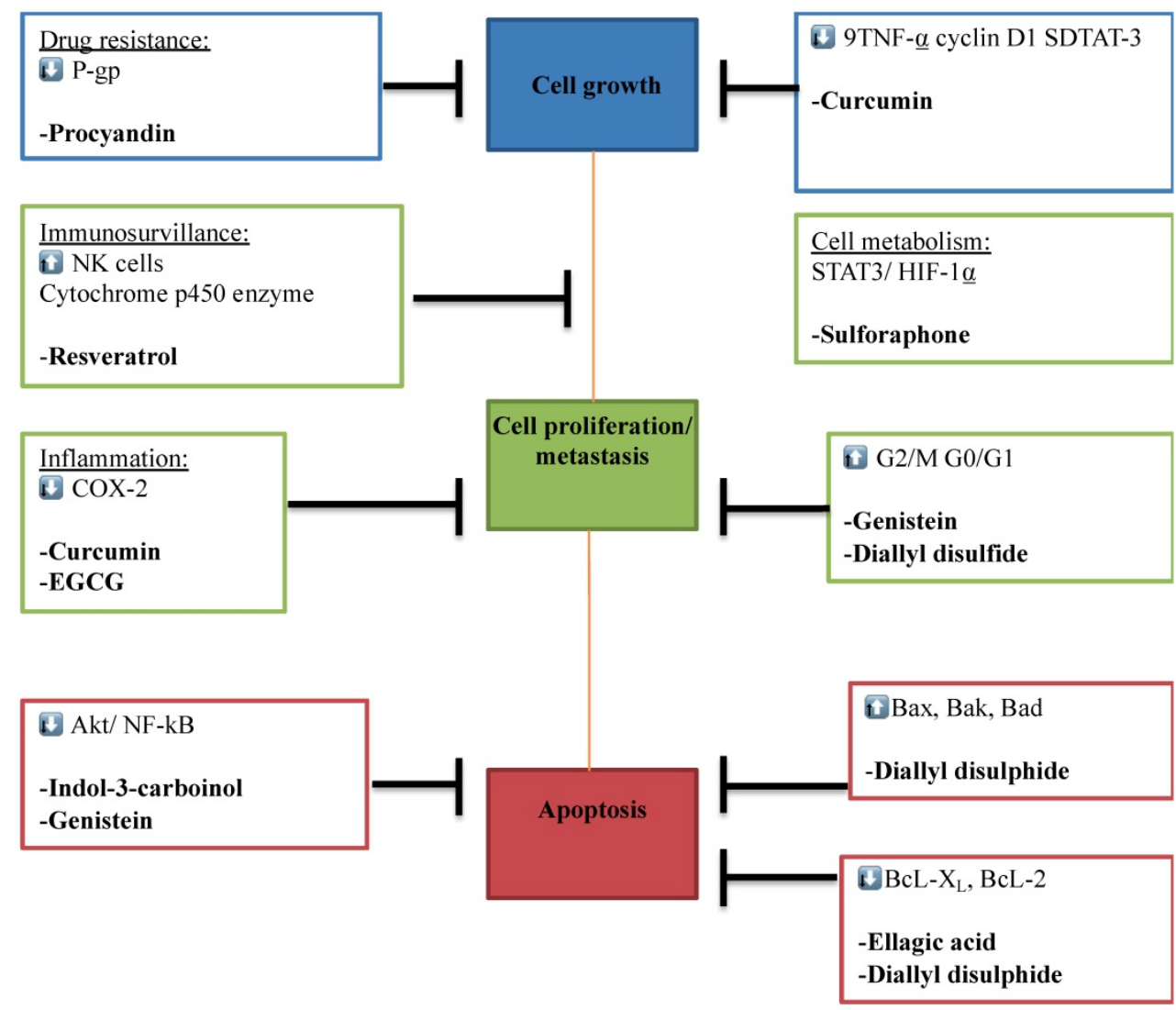

Figure 2. Multi-molecular anticancer target of phytochemicals. The Figure illustrates the different phytochemicals and their corresponding molecular targets that underpin their effects on tumor cell proliferation, invasion and metastasis, immune surveillance, drug resistance, inflammation, and tumor cell metabolism. 


\section{Quercetin}

Quercetin belongs to the class of polyphenolic flavonoid compounds ubiquitous in plant food sources and its average daily intake has been estimated at 25mg [91]. Animal and human studies have demonstrated that it is absorbed very well with an elimination half life of 25 hrs [91]. Serum concentrations of quercetin required for anti-cancer activity seems to be greater than $10 \mu \mathrm{M}$ [92]. A single dose of up to $4 \mathrm{gm}$ was not associated with any side effects [92]. It has been shown to possess mutagenic activity in the Ames test [93] but not carcinogenic activity [94]. Major molecular mechanisms of action of quercetin include down regulation of mutant p53 in breast cancer cells leading to G1 phase arrest of cell cycle [95], tyrosine kinase inhibition both in vitro and in vivo human studies [96], inhibition of heat shock protein and Ras proto-oncogene [97]. A number of these actions have also been demonstrated in ovarian cancer cells. It inhibited heat shock protein-70 [98]. It has been shown to sensitize with cisplatin in inhibiting SK-OV-3 and CAOV3 ovarian cancer cell proliferation [99]. Further Scambia et al. [100, 101] showed that quercetin treatment of OVCAR 433 ovarian cancer cells increased TGF- $\beta$ secretion over 24 hrs and this could be the cause for inhibition of cell proliferation, as administration of a monoclonal antibody to TGF- $\beta$ reversed these effects of quercetin. In cervical cancer, quercetin showed to reduce cell viability, colony formation and enhanced $\mathrm{G}_{2}-\mathrm{M}$ cell cycle arrest, DNA damage and apoptosis [102]. Furthermore, quercetin showed to inhibit PI3K, MAPK and WNT pathways [102]. Similarly, in melanoma cells, quercetin significantly reduced cellular viability and proliferation, and induced apoptosis involving JNK/P38 MAPK signaling activation [103].

\section{Dihydroartemisinin (DHA):}

DHA is a derivative of artemisinin, a compound extracted from the wormwood Artemisia annua, a species belonging to the daisy family and used by ancient Chinese herbalists to treat fevers. It has been shown to kill a variety of cancer cells by inducing apoptosis. It is cytotoxic to papilloma virus-expressing epithelial cells in vitro and in vivo [104] and induced apoptosis through activation of mitochondrial caspase pathway in a p53 independent manner. It downregulates VEGF expression in RPMI18226 multiple myeloma cells [105]. and further inhibits proliferation, migration and tube formation of HUVE cells. It exerts cytotoxic effects on C6 glioma cells and inhibits hypoxia inducible factor-1 a activation [106]. DHA has been shown to synergize with temozolomide to exert cytotoxic effects in rat C6 glioma cells [107]. It has been shown to bind to human fortillin; (an anti-apoptotic molecule overexpressed in many cancers) increased its ubiquitination and degradation. It induced DNA fragmentation in U205 cells in a fortillin dependent manner. Data indicate that fortillin is a molecular target of DHA. Developed as an antimalarial drug, it has undergone in vivo testing in animals and humans. It has shown to sensitize human ovarian cancer cells to carboplatin therapy [108]. Jiao et al [109] demonstrated that a panel of ovarian cancer cells were susceptible to treatment with dihydroartemisinin alone; the cancer cells lines were 5-10 fold more sensitive as compared to normal ovarian cell lines. It induced G2 cell cycle arrest, decrease in anti apoptotic proteins Bcl-xL, Bcl-2, increase in pro apoptotic proteins Bax and Bad [109].

\section{Procyanidin}

Procyanidin is found at high concentration in cocoa, berries, apple and grapes. Procyanidin increases mRNA expression of the tumor suppressor gene IGF-2R and PTEN, and is also, a potent inhibitor of P-gp (a multidrug resistant gene) [33], suggested additive to supplement conventional therapy. Recent evidence supports the chemo-preventive potential of procyanidin in lung and breast cancer $[33,110,111]$.

\section{Folate and folic acid}

Folate and Folic acid are extracted from asparagus, green leafy vegetables and broccoli [112]. Pre-clinical studies showed folate is involved in DNA repair and modulation of S-adenosylmethionine; a donor of a methyl group for DNA methylation. Multiple large-scale studies have suggested that dietary folate lowers risk of various cancers including stomach, lung, pancreatic, colorectal and breast cancer $[113,114]$.

\section{Lycopene}

Lycopene, a carotenoid extracted from vegetables and fruits is found in high concentration in tomatoes [115]. Lycopene reduces intercellular reactive oxygen species (ROS) by promoting antioxidants such as glutathione-S-transferase-omega-1 and superoxide dismutase-1 (SOD-1); by promoting ERO-1. Evidence shows that lycopene reduces ovarian tumor growth [116], leads to a reduced risk in breast and prostate tumor, and can also significantly inhibit the cellular growth of colorectal [117] and lung cancer [118]. Importantly, lycopene can also alleviate radiation-induced esophagitis [119] and cisplatin-induced nephropathy [120].

\section{Sulforaphane (SFN)}

Sulforaphane (SFN) is found in high concentrations in cauliflower, broccoli, and 
cruciferous vegetables. SFN was shown to suppress tumor angiogenesis by reducing cell viability, migration and tube formation in HUVEC-epithelial cell lines possibly through inhibition of signalling between STAT3/HIF-1a/VEGF [118]. It was recently shown to reduce YAP1 signaling leading to a reduction in cancer stem cell survival and tumor formation in epidermal squamous cell carcinoma [121].

\section{Indole-3-Carboinol (I3C)}

Indole-3-carbinol (I3C), a phytochemical extracted from cruciferous plants such as broccoli, cabbage and cauliflower, is known to prevent cancer development [122]. Its ability to cause G1 arrest of cell cycle, induction of apoptosis and to interfere with signal transduction pathways have been demonstrated in a variety of cancer cell lines, including prostate [123], melanoma [124] and breast cancer [125]. I3C protects the cell from oxidative stress resulting from the formation of reactive oxygen species (ROS). In the breast cancer cell line, MDA-MB-231, 3'-diindolylmethane, another member of I3C, suppresses activity of the Akt/NF-KB signaling pathway, promoting apoptosis and inhibits angiogenesis [122]. Ability of this compound to target multiple genes involved in both cell cycle (cyclin D1, cyclin E, cyclin-dependent kinases CDK2, CDK4 and CDK6) and apoptosis (Bcl-2, Bcl-xl, survivin, inhibitor of apoptosis protein IAP, $x$-chromosome linked IAP, pro-apoptotic gene Bax, activation of caspase- 9 and caspase 3) have been well documented [126]. In addition, it has been shown to inhibit activation of transcription factors including nuclear factor-kappa B, $\mathrm{SP} 1$, estrogen receptor, androgen receptor and nuclear factor-E2-related factor 2 (Nrf2). It has a strong hepatoprotective activity against various carcinogens. Due to its broad spectrum of activities, combined with low toxicity, I3C has been acclaimed as a potent chemopreventive and anti-cancer agent [127]. The effects of this compound on various cancers and mechanisms of action have been reviewed [126, 128]. Howells et al. [43] have reviewed the bioavailability of I3C, and showed that plasma levels of $4 \mu \mathrm{g} / \mathrm{ml}$ was achieved with feeding a dose of $250 \mathrm{mg} / \mathrm{kg}$. Work in our laboratory demonstrated a synergistic effect of resveratrol with I3C to inhibit ovarian cancer cell proliferation [122, 129]. The effects of resveratrol on cell proliferation and $\mathrm{G} 2 / \mathrm{M}$ phase of cell cycle were potentiated by addition of I3C $[122,129]$.

\section{Ellagic acid}

Ellagic acid, found in Punica granatum (pomegranate), exhibits anti-proliferative capacities and promotes apoptosis in prostate cancer cells via the cyclin kinase inhibitor-cyclin cdk machinery. Ellagic acid down regulates Bcl- $\mathrm{X}_{\mathrm{L}}$ and BcL-2; cyclins D1, D2, cdk 2, 4 and 6 [130]. Ellagic acid was also shown to reduce metastasis in breast [131] and ovarian cancer [132]. Studies have indicated ellagic acid to have anti-cancer effects due to its ability to target histone deacetylase 6-related pathways [133].

\section{Genistein}

Genistein, an isoflavone found primarily in soybeans, modulates multi-signalling targets in cancer cells. This bioactive compound modulates the cell cycle and apoptosis process of prostate, breast and lung cancer cell lines by inhibiting NF-kB and Akt signalling pathway and promotes G2/M and G0/G1 arrest in various cancer cell lines [134]. Genistein downregulates anti-apoptotic proteins $\mathrm{BCL}-\mathrm{X}_{\mathrm{L}}$ and BcL-2 and upregulates pro-apoptotic Bax, Bak, and Bad proteins [134]. Chemotherapeutic agents such as docetaxel, gemcitabine and cisplatin promote NF-kB activation in cancer cells - a possible cause of drug resistance [135]. Pre-treatment with genistein in in-vivo and in-vitro models reduced cell growth and promoted apoptosis when compared to chemotherapeutic treatments alone [136].

\section{Diallyl disulfide}

Diallyl disulfide found in cauliflower, broccoli and cabbage was shown to promote G2/M cell cycle arrest by generating ROS and reducing the HDAC activity in cancer cells [137].

\section{Perspectives: Phytochemical Combination Studies}

Many of these herbs and their extracts are further mixed and prescribed in Asian countries for chronic diseases such as arthritis, diabetes and cancers. There have been many claims by the practitioners in India, China and other asian countries, of having cured cancers. The senior author has met several of them, visited their 'clinics', seen their 'patients' who have been claimed to have been rescued from terminal stage neuroblastoma and adenocarcinomas. A common feature of these practitioners has been a reluctance to subject their herbal preparations to clinical trials using accepted parameters (double blind, randomized, cross-over studies or case control studies). In the US, they are not approved by the regulating bodies such as FDA for treating specific diseases, but are sold extensively over the counter as nutritional dietary supplements. Research in this exciting area has been intense and has succeeded in identifying several active compounds (such as the ones described in this review), purification, characterization and structure 
elucidation of these compounds and structurefunction studies leading to identification of more potent analogues. Molecular mechanisms of action of these compounds is being investigated widely [122, 129]. Many of these have been tested individually and in combination of 2 or 3 together and have shown additive and synergistic properties [122, 129]. However, combination studies using several of these together have not been explored, and molecular mechanisms of such combinations need to be investigated. The ability of such multiple combinations to cause complete and permanent remission of cancers need to be evaluated.

The preceding discussion of literature on these various phytochemicals demonstrates that 1 ) each of these chemicals has multiple effects and targets multiple pathways in the cancer cell, 2) an additive or synergistic action was noted upon combination of two and sometimes three compounds [122, 129], 3) a striking feature of low toxicity combined with effective absorption upon oral administration , 4) many of these compounds have effects on, not one but many different cancers, and 5) each of these pyto-chemicals has many common mechanisms with others, and acts on pathways in a manner unique to themselves. Molecular mechanism of action of these compounds is being investigated widely [122, 129]. Many of these have been tested individually and in combination of two and have shown additive and synergistic properties. However, combination studies using several of these together have not been investigated and molecular mechanisms of such combinations need to be determined. The ability of such multiple combinations to cause complete and permanent remission of cancers need to be evaluated.

Our recent work demonstrated synergism between several compounds [122, 129]. Our recent results demonstrated the effectiveness of different combinations in causing $100 \%$ inhibition of breast cancer cell proliferation, by a combination of five phytochemicals used at bioavailable concentrations $([122,129]$. These results pave the way to evaluate their effectiveness in vivo. The main objective of our proposal is to elucidate unique molecular mechanisms that contribute to increased effectiveness of these phytochemicals when used in combination to inhibit ovarian epithelial carcinoma. This data prompted us to generate several hypotheses that: 1) Cell proliferation inhibitory activity of phytochemical combination is the result of synergistic and additive actions of the individual selected phytochemicals; 2) combination of these phytochemicals activates gene(s) that are exclusive to the combination; 3) identification of these gene(s) unique to the combination, have the potential to be used for the design of targeted therapy of $\mathrm{BC}$ and 4) this combination of five will be effective in chemoprevention and chemotherapy of various cancers in in vivo. Our ongoing in vivo studies will shed light on the possibility of establishing specific phytochemical combinations to treat specific cancers. More interestingly, our genomic studies, using microarray or RNAseq technologies combined with functional studies will allow us the identification and validation of candidate genes that will pave the way towards the design of effective targeted therapeutic cancer strategies.

\section{Conclusion}

Cancer is a complex disease with various aetiologies, and conventional therapies cause multiple side effects, representing a serious economic challenge. There are more than 5000 phytochemicals found in fruits, grains and vegetables with a large amount still undiscovered [138]. The efficacy of a combination of phytochemicals in cancer therapy, maybe due to their ability in modulating different signaling pathways, at once, that promote cell death, inhibit cell proliferation and invasion, sensitize cancerous cells, and boost the immune system. Combinations of cytotoxic anti-tumour agents and inhibitors from phytochemicals might act together producing inhibitory mechanisms against tumor growth. While the combination of conventional and CAM therapies is a promising strategy, clinical studies are required to establish better anti-cancer treatments [139]. Moreover, preclinical and epidemiological studies are required to identify the molecular signatures of newly discovered phytochemicals and identify their associated carcinogenesis biomarkers.

\section{Acknowledgments}

This work was supported by the following Qatar University grants, grant numbers: QUUG-CAS-DBES15/16-22, QUST-CAS-SPR-15/16-14, QUST-2-CAS2017-16, and QUST-1-CAS-2019-2.

\section{Competing Interests}

The authors have declared that no competing interest exists.

\section{References}

1. L. A. Torre F, Bray, R.L. Siegel, J Ferlay, J Lortet-Tieulent, A. Jemal DVM. Global cancer statistics, 2012. CA Cancer J Clin. 2015; 65: 87-108.

2. Kawasaki B, Hurt EM, Mistree T, Farrar WL. Targeting cancer stem cells with phytochemicals. Mol Interv. 2008; 8: 174-84.

3. Lee KW, Bode AM, Dong Z. Molecular targets of phytochemicals for cancer prevention. Nature Reviews Cancer. 2011; 11: 211.

4. Howes M, Simmonds MS. The role of phytochemicals as micronutrients in health and disease. Curr Opin Clin Nutr Metab Care. 2014; 17: 558-66.

5. Surh Y-J. Cancer chemoprevention with dietary phytochemicals. Nature Reviews Cancer. 2003; 3: 768. 
6. Ramamurthi Vidya P, Siddavaram N. Cancer Chemoprevention by Dietary Phytochemicals: Promises and Pitfalls. Current Pharmaceutical Biotechnology. 2012; 13: 125-36.

7. Arruebo M, Vilaboa N, Sáez-Gutierrez B, Lambea J, Tres A, Valladares $\mathrm{M}$, et al. Assessment of the evolution of cancer treatment therapies. Cancers. 2011; 3: 3279-330.

8. Meyer LA, Bohlke K, Powell MA, Fader AN, Franklin GE, Lee LJ, et al. Postoperative Radiation Therapy for Endometrial Cancer: American Society of Clinical Oncology Clinical Practice Guideline Endorsement of the American Society for Radiation Oncology Evidence-Based Guideline. Journal of Clinical Oncology. 2015; 33: 2908-13.

9. Sethi A. Khan's Treatment Planning in Radiation Oncology, 4th Edition. Editor: Faiz M. Khan, John P. Gibbons, Paul W. Sperduto. Lippincott Williams \& Wilkins (Wolters Kluwer), Philadelphia, PA, 2016. 648 pp. Price: \$215.99. ISBN: 9781469889979. (Hardcover) $\left(^{*}\right)$. Medical Physics. 2018; 45: 2351-

10. Baskar R, Lee KA, Yeo R, Yeoh KW. Cancer and Radiation Therapy: Current Advances and Future Directions. Int J Med Sci. 2012; 9: 193-9.

11. Bandekar A, Zhu C, Jindal R, Bruchertseifer F, Morgenstern A, Sofou S. Anti-Prostate-Specific Membrane Antigen Liposomes Loaded with 225Ac for Potential Targeted Antivascular a-Particle Therapy of Cancer. Journal of Nuclear Medicine. 2014; 55: 107-14.

12. Emmett L, Willowson K, Violet J, Shin J, Blanksby A, Lee J. Lutetium 177 PSMA radionuclide therapy for men with prostate cancer: a review of the current literature and discussion of practical aspects of therapy. Journal of Medical Radiation Sciences. 2017; 64: 52-60.

13. R. Od, Oliveira, L.C. de Santa Maria, G., Barratt. Nanomedicine and its applications to the treatment of prostate cancer. Annales Pharmaceutiques Françaises. 2014; 72: 303-16.

14. Alfarouk KO, Stock C-M, Taylor S, Walsh M, Muddathir AK, Verduzco $\mathrm{D}$, et al. Resistance to cancer chemotherapy: failure in drug response from ADME to P-gp. Cancer Cell International. 2015; 15: 71.

15. Alizadeh E, Orlando TM, Sanche L. Biomolecular Damage Induced by Ionizing Radiation: The Direct and Indirect Effects of Low-Energy Electrons on DNA. Annual Review of Physical Chemistry. 2015; 66: 379-98

16. Cekici A, Kantarci A, Hasturk H, Van Dyke TE. Inflammatory and immune pathways in the pathogenesis of periodontal disease. Periodontology 2000. 2014; 64: 57-80.

17. Srivastava PKR. Nanomedicine for Cancer Therapy. In: From Chemotherapeutic to Hyperthermia-Based Therapy. Springer International Publishing. 1999.

18. Datta NR, Ordóñez SG, Gaipl US, Paulides MM, Crezee H, Gellermann J, et al. Local hyperthermia combined with radiotherapy and-/or chemotherapy: Recent advances and promises for the future. Cancer Treatment Reviews. 2015; 41: 742-53.

19. Reyes-Habito C, Roh EK. Cutaneous reactions to chemotherapeutic drugs and targeted therapy for cancer: Part II. Targeted therapy. J Am Acad Dermatol. 2014; 71: e1-217.

20. Klener P, Etrych T, Klener P. Biological therapy of hematologic malignancies: toward a chemotherapy-free era. Curr Med Chem. 2017; [Epub ahead of print].

21. Stjepanovic N, Velazquez-Martin JP, Bedard PL. Ocular toxicities of MEK inhibitors and other targeted therapies. Annals of Oncology. 2016; 27: 998-1005.

22. Doll R, Peto R. The causes of cancer: quantitative estimates of avoidable risks of cancer in the United States today. J Natl Cancer Inst. 1981; 66: 1191-308.

23. Mohd Mujar NM, Dahlui M, Emran NA, Abdul Hadi I, Wai YY, Arulanantham S, et al. Complementary and alternative medicine (CAM) use and delays in presentation and diagnosis of breast cancer patients in public hospitals in Malaysia. PloS one. 2017; 12: e0176394-e.

24. Aleksandrova K, Pischon T, Jenab M, Bueno-de-Mesquita HB, Fedirko V, Norat $\mathrm{T}$, et al. Combined impact of healthy lifestyle factors on colorectal cancer: a large European cohort study. BMC Medicine. 2014; 12: 168.

25. Garcia DO, Thomson CA. Physical activity and cancer survivorship. Nutr Clin Pract. 2014; 29: 768-79.

26. Bouker KB, Hilakivi-Clarke L. Genistein: does it prevent or promote breast cancer? Environmental health perspectives. 2000; 108: 701-8.

27. Hui C, Qi X, Qianyong Z, Xiaoli P, Jundong Z, Mantian M. Flavonoids, flavonoid subclasses and breast cancer risk: a meta-analysis of epidemiologic studies. PloS one. 2013; 8: e54318-e.

28. Kotecha R, Takami A, Espinoza JL. Dietary phytochemicals and cancer chemoprevention: a review of the clinical evidence. Oncotarget. 2016; 7: 52517-29.

29. Lewis KA, Tollefsbol TO. The influence of an epigenetics diet on the cancer epigenome. Epigenomics. 2017; 9: 1153-5.
30. Braicu C, Mehterov N, Vladimirov B, Sarafian V, Nabavi SM, Atanasov AG, et al. Nutrigenomics in cancer: Revisiting the effects of natural compounds. Seminars in Cancer Biology. 2017; 46: 84-106.

31. Key TJ. Fruit and vegetables and cancer risk. British Journal Of Cancer. 2010; 104: 6.

32. Steinmetz KA, Potter JD. Vegetables, Fruit, and Cancer Prevention: A Review. Journal of the Academy of Nutrition and Dietetics. 1996; 96: 1027-39.

33. Lee Y. Cancer Chemopreventive Potential of Procyanidin. Toxicological research. 2017; 33: 273-82.

34. Lila MA, Raskin I. Health-related Interactions of Phytochemicals. Journal of Food Science. 2005; 70: R20-R7.

35. Pöch G. Combined Effects of Drugs and Toxic Agents. In: Modern Evaluation in Theory and Practice. Springer-Verlag Wien. 1999.

36. Shukla S, Penta D, Mondal P, Meeran SM. Epigenetics of Breast Cancer: Clinical Status of Epi-drugs and Phytochemicals. In: Ahmad A, editor. Breast Cancer Metastasis and Drug Resistance: Challenges and Progress. Cham: Springer International Publishing; 2019:293-310.

37. Sharma P, Montes de Oca MK, Alkeswani AR, McClees SF, Das T, Elmets CA, et al. Tea polyphenols for the prevention of UVB-induced skin cancer. Photodermatology, Photoimmunology \& Photomedicine. 2018; 34: 50-9.

38. Meeran SM, Akhtar S, Katiyar SK. Inhibition of UVB-induced skin tumor development by drinking green tea polyphenols is mediated through DNA repair and subsequent inhibition of inflammation. The Journal of investigative dermatology. 2009; 129: 1258-70.

39. Giudice A, Montella M, Boccellino M, Crispo A, D'Arena G, Bimonte S, Facchini G, Ciliberto G, Botti G, Quagliuolo L, Caraglia M, Capunzo M. Epigenetic Changes Induced by Green Tea Catechins a re Associated with Prostate Cancer. Current Molecular Medicine. 2017; 17: 405-20.

40. Chikara S, Nagaprashantha LD, Singhal J, Horne D, Awasthi S, Singhal SS. Oxidative stress and dietary phytochemicals: Role in cancer chemoprevention and treatment. Cancer Letters. 2018; 413: 122-34.

41. Jin G, Yang Y, Liu K, Zhao J, Chen X, Liu H, et al. Combination curcumin and (-)-epigallocatechin-3-gallate inhibits colorectal carcinoma microenvironment-induced angiogenesis by JAK/STAT3/IL-8 pathway. Oncogenesis. 2017; 6: e384-e.

42. Pistollato F, Calderón Iglesias R, Ruiz R, Aparicio S, Crespo J, Dzul Lopez $\mathrm{L}$, et al. The use of natural compounds for the targeting and chemoprevention of ovarian cancer. Cancer Letters. 2017; 411: 191-200.

43. Howells LM, Moiseeva EP, Neal CP, Foreman BE, Andreadi CK, Sun $\mathrm{Y}-\mathrm{y}$, et al. Predicting the physiological relevance of in vitro cancer preventive activities of phytochemicals. Acta Pharmacologica Sinica. 2007; 28: 1274.

44. Goel A, Jhurani S, Aggarwal BB. Multi-targeted therapy by curcumin: how spicy is it? Molecular Nutrition \& Food Research. 2008; 52: 1010-30.

45. Goel A, Kunnumakkara AB, Aggarwal BB. Curcumin as "Curecumin": from kitchen to clinic. Biochem Pharmacol. 2008; 75: 787-809.

46. Chen X, Aravindakshan J, Yang Y, Sairam MR. Early alterations in ovarian surface epithelial cells and induction of ovarian epithelial tumors triggered by loss of FSH receptor. Neoplasia. 2007; 9: 521-31.

47. Yang K-Y, Lin L-C, Tseng T-Y, Wang S-C, Tsai T-H. Oral bioavailability of curcumin in rat and the herbal analysis from Curcuma longa by LCMS/MS. Journal of Chromatography B. 2007; 853: 183-9.

48. Aedo-Aguilera V, Carrillo-Beltrán D., Calaf GM., et al. Curcumin decreases epithelial-mesenchymal transition by a Pirin-dependent mechanism in cervical cancer cells. Oncology Reports. 2019.

49. Inano $\mathrm{H}$, Onoda $\mathrm{M}$. Prevention of radiation-induced mammary tumors. International Journal of Radiation Oncology • Biology • Physics. 2002; 52: $212-23$.

50. Frank N, Knauft J, Amelung F, Nair J, Wesch H, Bartsch H. No prevention of liver and kidney tumors in Long-Evans Cinnamon rats by dietary curcumin, but inhibition at other sites and of metastases. Mutation Research/Fundamental and Molecular Mechanisms of Mutagenesis. 2003; 523-524: 127-35.

51. Busquets S, Carbo N, Almendro V, Quiles MT, Lopez-Soriano FJ, Argiles JM. Curcumin, a natural product present in turmeric, decreases tumor growth but does not behave as an anticachectic compound in a rat model. Cancer Lett. 2001; 167: 33-8.

52. Menon LG, Kuttan R, Kuttan G. Inhibition of lung metastasis in mice induced by B16F10 melanoma cells by polyphenolic compounds. Cancer Letters. 1995; 95: 221-5.

53. Zhang L, Tao X., Fu Q., et al. Curcumin inhibits cell proliferation and migration in NSCLC through a synergistic effect on the TLR4/MyD88 and EGFR pathways. Oncology Reports. 2019.

54. Verma SP, Salamone E, Goldin B. Curcumin and Genistein, Plant Natural Products, Show Synergistic Inhibitory Effects on the Growth of Human Breast Cancer MCF-7 Cells Induced by Estrogenic Pesticides. 
Biochemical and Biophysical Research Communications. 1997; 233: 692-6.

55. Khafif A, Schantz SP, Chou TC, Edelstein D, Sacks PG. Quantitation of chemopreventive synergism between (-)-epigallocatechin-3-gallate and curcumin in normal, premalignant and malignant human oral epithelial cells. Carcinogenesis. 1998; 19: 419-24.

56. Deeb D, Xu YX, Jiang H, Gao X, Janakiraman N, Chapman RA, et al. Curcumin (Diferuloyl-Methane) Enhances Tumor Necrosis Factor-related Apoptosis-inducing Ligand-induced Apoptosis in LNCaP Prostate Cancer Cells $<a \quad$ id="xref-fn-2-1" class="xref-" href="\#fn-2" $><$ sup $>1</$ sup $></ a>$. Molecular Cancer Therapeutics. 2003; 2: 95-103.

57. Bortel N, Armeanu-Ebinger S, Schmid E, Kirchner B, Frank J, Kocher A, et al. Effects of curcumin in pediatric epithelial liver tumors: inhibition of tumor growth and alpha-fetoprotein in vitro and in vivo involving the NFkappaB- and the beta-catenin pathways. Oncotarget. 2015; 6: 40680-91.

58. Shehzad A, Wahid F, Lee YS. Curcumin in Cancer Chemoprevention: Molecular Targets, Pharmacokinetics, Bioavailability, and Clinical Trials. Archiv der Pharmazie. 2010; 343: 489-99.

59. Dharmalingam S, Gaurav K, Prasad D, Shrikant A. Targeting Cancer Stem Cells for Chemoprevention of Pancreatic Cancer. Current Medicinal Chemistry. 2018; 25: 2585-94.

60. Wang Y, Bu C., Wu K., Wang R., Wang J. Curcumin protects the pancreas from acute pancreatitis via the mitogen-activated protein kinase signaling pathway. Molecular Medicine Reports. 2019; 20: 3027-34.

61. Kamat AM, Sethi G, Aggarwal BB. Curcumin potentiates the apoptotic effects of chemotherapeutic agents and cytokines through down-regulation of nuclear factor- $\mathrm{kB}$ and nuclear factor-kB-regulated gene products in IFN- $\alpha$-sensitive and IFN- $\alpha-$ resistant human bladder cancer cells. Molecular Cancer Therapeutics. 2007; 6: 1022-30.

62. Cruz-Correa M, Shoskes DA, Sanchez P, Zhao R, Hylind LM, Wexner $\mathrm{SD}$, et al. Combination Treatment With Curcumin and Quercetin of Adenomas in Familial Adenomatous Polyposis. Clinical Gastroenterology and Hepatology. 2006; 4: 1035-8.

63. Siddappa G, Kulsum S, Ravindra DR, Kumar VV, Raju N, Raghavan N, et al. Curcumin and metformin-mediated chemoprevention of oral cancer is associated with inhibition of cancer stem cells. Molecular Carcinogenesis. 2017; 56: 2446-60.

64. Barve A, Khor TO, Hao X, Keum Y-S, Yang CS, Reddy B, et al. Murine Prostate Cancer Inhibition by Dietary Phytochemicals-Curcumin and Phenyethylisothiocyanate. Pharmaceutical Research. 2008; 25: 2181-9.

65. Lin YG, Kunnumakkara AB, Nair A, Merritt WM, Han LY, Armaiz-Pena GN, et al. Curcumin Inhibits Tumor Growth and Angiogenesis in Ovarian Carcinoma by Targeting the Nuclear Factor-kB Pathway. Clinical Cancer Research. 2007; 13: 3423-30.

66. Weir NM, Selvendiran K, Kutala VK, Tong L, Vishwanath S, Rajaram M, et al. Curcumin induces G2/M arrest and apoptosis in cisplatin-resistant human ovarian cancer cells by modulating Akt and p38 MAPK. Cancer biology \& therapy. 2007; 6: 178-84.

67. Wahl H, Tan L, Griffith K, Choi M, Liu JR. Curcumin enhances Apo2L/TRAIL-induced apoptosis in chemoresistant ovarian cancer cells. Gynecologic Oncology. 2007; 105: 104-12.

68. Valentine SP, Le Nedelec MJ, Menzies AR, Scandlyn MJ, Goodin MG, Rosengren RJ. Curcumin modulates drug metabolizing enzymes in the female Swiss Webster mouse. Life Sciences. 2006; 78: 2391-8.

69. Grill AE, Shahani K, Koniar B, Panyam J. Chemopreventive efficacy of curcumin-loaded PLGA microparticles in a transgenic mouse model of HER-2-positive breast cancer. Drug Delivery and Translational Research. 2018; 8: 329-41.

70. Notas G, Nifli A-P, Kampa M, Vercauteren J, Kouroumalis E, Castanas E. Resveratrol exerts its antiproliferative effect on HepG2 hepatocellular carcinoma cells, by inducing cell cycle arrest, and NOS activation. Biochimica et Biophysica Acta (BBA) - General Subjects. 2006; 1760: 1657-66.

71. Yang SH, Kim JS., Oh TJ., et al. Genome-scale analysis of resveratrol-induced gene expression profile in human ovarian cancer cells using a cDNA microarray. International Journal of Oncology. 2003; 22: 741-50.

72. Benitez FJ, Acero JL, Leal AI, Real FJ. Ozone and membrane filtration based strategies for the treatment of cork processing wastewaters. J Hazard Mater. 2008; 152: 373-80.

73. Fulda SD, K.M. Sensitization for tumor necrosis factor-related apoptosis-inducing ligand-induced apoptosis by the chemopreventive agent resveratrol. Cancer Research. 2004; 64: 337-46.

74. Aggarwal BB, Bhardwaj A, Aggarwal RS, Seeram NP, Shishodia S, Takada Y. Role of Resveratrol in Prevention and Therapy of Cancer: Preclinical and Clinical Studies. Anticancer Research. 2004; 24: 2783-840.
75. Baur JA, Sinclair DA. Therapeutic potential of resveratrol: the in vivo evidence. Nature Reviews Drug Discovery. 2006; 5: 493.

76. BHAT KPL, PEZZUTO JM. Cancer Chemopreventive Activity of Resveratrol. Annals of the New York Academy of Sciences. 2002; 957: 210-29.

77. Singh R, Agarwal R. Cancer Research. 2000. p. 5617.

78. Arabshahi A, Patel BB, Harper CE, Wang J, Lamartiniere CA, Eltoum IA. Resveratrol suppresses prostate cancer progression in transgenic mice. Carcinogenesis. 2007; 28: 1946-53.

79. Kueck A, Opipari AW, Griffith KA, Tan L, Choi M, Huang J, et al. Resveratrol inhibits glucose metabolism in human ovarian cancer cells. Gynecologic Oncology. 2007; 107: 450-7

80. Opipari AW, Tan L, Boitano AE, Sorenson DR, Aurora A, Liu JR. Resveratrol-induced Autophagocytosis in Ovarian Cancer Cells. Cancer Research. 2004; 64: 696-703.

81. Park SY, Jeong KJ, Lee J, Yoon DS, Choi WS, Kim YK, et al. Hypoxia enhances LPA-induced HIF-1a and VEGF expression: Their inhibition by resveratrol. Cancer Letters. 2007; 258: 63-9.

82. Aggarwal BB. Resveratrol: A multitargeted agent for age-associated chronic diseases AU - Harikumar, Kuzhuvelil B. Cell Cycle. 2008; 7: 1020-35.

83. Pirola L, Fröjdö S. Resveratrol: One molecule, many targets. IUBMB Life. 2008; 60: 323-32.

84. Rezk YA, Balulad SS, Keller RS, Bennett JA. Use of Resveratrol to improve the effectiveness of cisplatin and doxorubicin: Study in human gynecologic cancer cell lines and in rodent heart. American Journal of Obstetrics \& Gynecology. 2006; 194: e23-e6.

85. Chow HHS, Garland LL, Hsu C-H, Vining DR, Chew WM, Miller JA, et al. Resveratrol modulates drug- and carcinogen-metabolizing enzymes in a healthy volunteer study. Cancer prevention research (Philadelphia, Pa). 2010; 3: 1168-75.

86. Guerra N, Tan YX, Joncker NT, Choy A, Gallardo F, Xiong N, et al. NKG2D-deficient mice are defective in tumor surveillance in models of spontaneous malignancy. Immunity. 2008; 28: 571-80.

87. Kumar A, Rimando AM, Levenson AS. Resveratrol and pterostilbene as a microRNA-mediated chemopreventive and therapeutic strategy in prostate cancer. Annals of the New York Academy of Sciences. 2017; 1403: 15-26.

88. Lee P-S, Chiou Y-S, Ho C-T, Pan M-H. Chemoprevention by resveratrol and pterostilbene: Targeting on epigenetic regulation. BioFactors. 2018; 44: 26-35.

89. Buhrmann C, Shayan P, Goel A, Shakibaei M. Resveratrol Regulates Colorectal Cancer Cell Invasion by Modulation of Focal Adhesion Molecules. Nutrients. 2017; 9: 1073.

90. He L, Fan F, Hou X, Gao C, Meng L, Meng S, et al. Resveratrol suppresses pulmonary tumor metastasis by inhibiting platelet-mediated angiogenic responses. Journal of Surgical Research. 2017; 217: 113-22.

91. Lamson D, Brignall MS. Antioxidants and cancer, part 3: quercetin. Altern Med Rev. 2000; 5: 196-208.

92. Gugler R, Leschik M, Dengler HJ. Disposition of quercetin in man after single oral and intravenous doses. European Journal of Clinical Pharmacology. 1975; 9: 229-34.

93. Bjeldanes L, Chang G. Mutagenic activity of quercetin and related compounds. Science. 1977; 197: 577-8.

94. Ambrose AM, Robbins DJ, Deeds F. Comparative toxicities of quercetin and quercitrin. Journal of the American Pharmaceutical Association. 1952; 41: 119-22.

95. Avila MA, Velasco JA, Cansado J, Notario V. Quercetin Mediates the Down-Regulation of Mutant p53 in the Human Breast Cancer Cell Line MDA-MB468. Cancer Research. 1994; 54: 2424-8.

96. Ferry DR, Smith A, Malkhandi J, Fyfe DW, deTakats PG, Anderson D, et al. Phase I clinical trial of the flavonoid quercetin: pharmacokinetics and evidence for in vivo tyrosine kinase inhibition. Clinical Cancer Research. 1996; 2: 659-68.

97. Ranelletti FO, Maggiano N, Serra FG, Ricci R, Larocca LM, Lanza P, et al. Quercetin inhibits p21-RAS expression in human colon cancer cell lines and in primary colorectal tumors. International Journal of Cancer. 2000; 85: $438-45$.

98. Hansen RK, Oesterreich S, Lemieux P, Sarge KD, Fuqua SAW. Quercetin Inhibits Heat Shock Protein Induction but Not Heat Shock Factor DNA-Binding in Human Breast Carcinoma Cells. Biochemical and Biophysical Research Communications. 1997; 239: 851-6.

99. Chan MM, Fong D, Soprano KJ, Holmes WF, Heverling H. Inhibition of growth and sensitization to cisplatin-mediated killing of ovarian cancer cells by polyphenolic chemopreventive agents. Journal of Cellular Physiology. 2003; 194: 63-70.

100. Scambia G, Ranelletti FO, Panici PB, Piantelli M, Bonanno G, De Vincenzo R, et al. Inhibitory effect of quercetin on primary ovarian and endometrial cancers and synergistic activity with 
cis-diamminedichloroplatinum(II). Gynecologic Oncology. 1992; 45: 13-9.

101. Scambia G, Ranelletti FO, Panici PB, Piantelli M, Bonanno G, De Vincenzo R, et al. Inhibitory effect of quercetin on OVCA 433 cells and presence of type II oestrogen binding sites in primary ovarian tumours and cultured cells. British journal of cancer. 1990; 62: 942-6.

102. Kedhari Sundaram M, Raina R, Afroze N, Bajbouj K, Hamad M, Haque $\mathrm{S}$, et al. Quercetin modulates signaling pathways and induces apoptosis in cervical cancer cells. Biosci Rep. 2019; 39: BSR20190720.

103. Kim S-H, Yoo E-S, Woo J-S, Han S-H, Lee J-H, Jung S-H, et al. Antitumor and apoptotic effects of quercetin on human melanoma cells involving JNK/P38 MAPK signaling activation. European Journal of Pharmacology. 2019; 860: 172568.

104. Disbrow GL, Baege AC, Kierpiec KA, Yuan H, Centeno JA, Thibodeaux CA, et al. Dihydroartemisinin Is Cytotoxic to Papillomavirus-Expressing Epithelial Cells <em>In vitro</em> and <em>In vivo</em>. Cancer Research. 2005; 65: 10854-61.

105. Wu X-H, Zhou H-J, Lee J. Dihydroartemisinin inhibits angiogenesis induced by multiple myeloma RPMI8226 cells under hypoxic conditions via downregulation of vascular endothelial growth factor expression and suppression of vascular endothelial growth factor secretion. Anti-Cancer Drugs. 2006; 17: 839-48.

106. Huang X-J, Ma Z-Q, Zhang W-P, Lu Y-B, Wei E-Q. Dihydroartemisinin exerts cytotoxic effects and inhibits hypoxia inducible factor-1a activation in C6 glioma cells. Journal of Pharmacy and Pharmacology. 2007; 59: 849-56.

107. Huang XJ, Li CT, Zhang WP, Lu YB, Fang SH, Wei EQ. Dihydroartemisinin Potentiates the Cytotoxic Effect of Temozolomide in Rat C6 Glioma Cells. Pharmacology. 2008; 82: 1-9.

108. Chen T, Li M, Zhang R, Wang H. Dihydroartemisinin induces apoptosis and sensitizes human ovarian cancer cells to carboplatin therapy. Journal of cellular and molecular medicine. 2009; 13: 1358-70.

109. Jiao Y, Ge C-m, Meng Q-h, Cao J-p, Tong J, Fan S-j. Dihydroartemisinin is an inhibitor of ovarian cancer cell growth. Acta Pharmacologica Sinica. 2007; $28: 1045$.

110. Lewandowska U, Szewczyk K, Owczarek K, Hrabec Z, Podsędek A, Sosnowska D, Hrabec E. Procyanidins from evening primrose (Oenothera paradoxa) defatted seeds inhibit invasiveness of breast cancer cells and modulate the expression of selected genes involved in angiogenesis, metastasis, and apoptosis. Nutr Cancer. 2013; 65: 1219-31.

111. Mao JT, Smoake J, Park HK, Lu Q-Y, Xue B. Grape Seed Procyanidin Extract Mediates Antineoplastic Effects against Lung Cancer via Modulations of Prostacyclin and 15-HETE Eicosanoid Pathways. Cancer Prevention Research. 2016; 9: 925-32.

112. Dary O. Nutritional interpretation of folic acid interventions. Nutrition Reviews. 2009; 67: 235-44

113. Lamprecht SA, Lipkin M. Chemoprevention of colon cancer by calcium, vitamin D and folate: molecular mechanisms. Nature Reviews Cancer. 2003; 3: 601.

114. Tio M, Andrici J, Cox MR, Eslick GD. Folate intake and the risk of upper gastrointestinal cancers: A systematic review and meta-analysis. Journal of Gastroenterology and Hepatology. 2014; 29: 250-8.

115. Palozza PP, Catalano A, Simone R. Tomato Lycopene and Inflammatory Cascade: Basic Interactions and Clinical Implications. Curr Med Chem. 2010; 17: 2547-63.

116. Holzapfel NP, Shokoohmand A, Wagner F, Landgraf M, Champ S, Holzapfel BM, et al. Lycopene reduces ovarian tumor growth and intraperitoneal metastatic load. American journal of cancer research. 2017; 7: 1322-36.

117. Huang J, Lu M-S, Fang Y-J, Xu M, Huang W-Q, Pan Z-Z, et al. Serum carotenoids and colorectal cancer risk: A case-control study in Guangdong, China. Molecular Nutrition \& Food Research. 2017; 61: 1700267.

118. Aizawa K, Liu C, Tang S, Veeramachaneni S, Hu K-Q, Smith DE, et al. Tobacco carcinogen induces both lung cancer and non-alcoholic steatohepatitis and hepatocellular carcinomas in ferrets which can be attenuated by lycopene supplementation. International journal of cancer. 2016; 139: 1171-81.

119. Coskun H, Andic F, Daglıoglu YK, Doran F, Sahin K, Tunalı C, Kucuk O. Lycopene in the Prevention of Radiation-Induced Esophagitis. Nutr Cancer. 2017; 69: 319-29.

120. Mahmoodnia L, Mohammadi K, Masumi R. Ameliorative effect of lycopene effect on cisplatin-induced nephropathy in patient. Journal of nephropathology. 2017; 6: 144-9.

121. Fisher ML, Ciavattone N, Grun D, Adhikary G, Eckert RL. Sulforaphane reduces $\mathrm{YAP} / \triangle \mathrm{Np} 63 \mathrm{a}$ signaling to reduce cancer stem cell survival and tumor formation. Oncotarget. 2017; 8: 73407-18.

122. Ouhtit A, Gaur RL, Abdraboh M, Ireland SK, Rao PN, Raj SG, et al. Simultaneous inhibition of cell-cycle, proliferation, survival, metastatic pathways and induction of apoptosis in breast cancer cells by a phytochemical super-cocktail: genes that underpin its mode of action. Journal of Cancer. 2013; 4: 703-15.

123. Chinni SR, Li Y, Upadhyay S, Koppolu PK, Sarkar FH. Indole-3-carbinol (I3C) induced cell growth inhibition, G1 cell cycle arrest and apoptosis in prostate cancer cells. Oncogene. 2001; 20: 2927.

124. Kim D-S, Jeong Y-M, Moon S-I, Kim S-Y, Kwon S-B, Park E-S, et al. Indole-3-carbinol enhances ultraviolet B-induced apoptosis by sensitizing human melanoma cells. Cellular and Molecular Life Sciences CMLS. 2006; 63: 2661-8.

125. Kim YS, Milner JA. Targets for indole-3-carbinol in cancer prevention. The Journal of Nutritional Biochemistry. 2005; 16: 65-73.

126. Ichikawa H. Molecular Targets and Anticancer Potential of Indole-3-Carbinol and Its Derivatives AU - Aggarwal, Bharat B. Cell Cycle. 2005; 4: 1201-15.

127. Weng J-R, Tsai C-H, Kulp SK, Chen C-S. Indole-3-carbinol as a chemopreventive and anti-cancer agent. Cancer letters. 2008; 262: 153-63.

128. Tsuda H, Ohshima Y, Nomoto H, Fujita K-i, Matsuda E, Iigo M, et al. Cancer Prevention by Natural Compounds. Drug Metabolism and Pharmacokinetics. 2004; 19: 245-63.

129. Raj MHG, Abd Elmageed ZY, Zhou J, Gaur RL, Nguyen L, Azam GA, et al. Synergistic action of dietary phyto-antioxidants on survival and proliferation of ovarian cancer cells. Gynecologic oncology. 2008; 110: 432-8.

130. Bell C, Hawthorne S. Ellagic acid, pomegranate and prostate cancer - a mini review. Journal of Pharmacy and Pharmacology. 2008; 60: 139-44.

131. Wang N, Wang Q, Tang H, Zhang F, Zheng Y, Wang S, et al. Direct inhibition of ACTN4 by ellagic acid limits breast cancer metastasis via regulation of $\beta$-catenin stabilization in cancer stem cells. Journal of Experimental \& Clinical Cancer Research. 2017; 36: 172.

132. Liu H, Zeng Z, Wang S, Li T, Mastriani E, Li Q-H, et al. Main components of pomegranate, ellagic acid and luteolin, inhibit metastasis of ovarian cancer by down-regulating MMP2 and MMP9. Cancer biology \& therapy. 2017; 18: 990-9.

133. Lernoux M, Schnekenburger M, Dicato M, Diederich M. Anti-cancer effects of naturally derived compounds targeting histone deacetylase 6-related pathways. Pharmacological Research. 2018; 129: 337-56.

134. Banerjee S, Li Y, Wang Z, Sarkar FH. Multi-targeted therapy of cancer by genistein. Cancer letters. 2008; 269: 226-42.

135. Voutsadakis IA. Molecular predictors of gemcitabine response in pancreatic cancer. World journal of gastrointestinal oncology. 2011; 3: 153-64.

136. Liu D, Yan L, Wang L, Tai W, Wang W, Yang C. Genistein enhances the effect of cisplatin on the inhibition of non-small cell lung cancer A549 cell growth in vitro and in vivo. Oncology letters. 2014; 8: 2806-10.

137. González-Vallinas M, González-Castejón M., Rodríguez-Casado A., Molina A.R. Dietary phytochemicals in cancer prevention and therapy: a complementary approach with promising perspectives. Nutrition reviews. 2013; 71: 585-99.

138. Mollakhalili Meybodi N, Mortazavian AM, Bahadori Monfared A, Sohrabvandi S, Aghaei Meybodi F. Phytochemicals in Cancer Prevention: A Review of the Evidence. Int J Cancer Manag. 2017; 10: e7219.

139. Knobloch TJ, Uhrig LK, Pearl DK, Casto BC, Warner BM, Clinton SK, et al. Suppression of Proinflammatory and Prosurvival Biomarkers in Oral Cancer Patients Consuming a Black Raspberry Phytochemical-Rich Troche. Cancer Prevention Research. 2016; 9: 159-71.

140. Lee CM, Lee J, Nam MJ, Park S-H. Indole-3-Carbinol Induces Apoptosis in Human Osteosarcoma MG-63 and U2OS Cells. Biomed Res Int. 2018; 2018: 7970618-

141. Mohammadi S, Seyedhosseini FS, Behnampour N, Yazdani Y. Indole-3-carbinol induces G1 cell cycle arrest and apoptosis through aryl hydrocarbon receptor in THP-1 monocytic cell line. Journal of Receptors and Signal Transduction. 2017; 37: 506-14.

142. Nakamura Y, Yogosawa S, Izutani Y, Watanabe H, Otsuji E, Sakai T. A combination of indol-3-carbinol and genistein synergistically induces apoptosis in human colon cancer HT-29 cells by inhibiting Akt phosphorylation and progression of autophagy. Mol Cancer. 2009; 8: $100-$.

143. J. Meng G-J, Liu, J.-Y. Song, L. Chen, A.-H. Wang, X.-X. Gao, Z.-J. Wang. Preliminary results indicate resveratrol affects proliferation and apoptosis of leukemia cells by regulating PTEN/PI3K/AKT pathway. Eur Rev Med Pharmacol Sci. 2019; 23: 4285-92.

144. Wang D, Gao Z, Zhang X. Resveratrol Induces Apoptosis in Murine Prostate Cancer Cells via Hypoxia-Inducible Factor 1-alpha (HIF-1a)/ Reactive Oxygen Species (ROS)/P53 Signaling. Med Sci Monit. 2018; 24: 8970-6. 
145. Wu Z, Liu B., et al. Resveratrol inhibits the proliferation of human melanoma cells by inducing G1/S cell cycle arrest and apoptosis. Molecular Medicine Reports. 2015; 11: 400-4.

146. Rasheduzzaman M, Jeong J-K, Park S-Y. Resveratrol sensitizes lung cancer cell to TRAIL by p53 independent and suppression of Akt/NF-kB signaling. Life Sciences. 2018; 208: 208-20.

147. Geng W, Guo X, Zhang L, Ma Y, Wang L, Liu Z, et al. Resveratrol inhibits proliferation, migration and invasion of multiple myeloma cells via NEAT1-mediated Wnt/ $\beta$-catenin signaling pathway. Biomedicine \& Pharmacotherapy. 2018; 107: 484-94.

148. Zininga T, Ramatsui L, Makhado PB, Makumire S, Achilinou I, Hoppe H, et al. (-)-Epigallocatechin-3-Gallate Inhibits the Chaperone Activity of Plasmodium falciparum Hsp70 Chaperones and Abrogates Their Association with Functional Partners. Molecules. 2017; 22: 2139.

149. Moses MA, Henry EC, Ricke WA, Gasiewicz TA. The heat shock protein 90 inhibitor, (-)-epigallocatechin gallate, has anticancer activity in a novel human prostate cancer progression model. Cancer prevention research (Philadelphia, Pa). 2015; 8: 249-57.

150. Wang W HX, Shen D, Ming Z, Zheng M, Zhang J. Polyphenol epigallocatechin-3-gallate inhibits hypoxia/reoxygenation-induced H9C2 cell apoptosis. Minerva Med. 2018; 109: 95-102.

151. Luo HQ, Xu M, Zhong WT, Cui ZY, Liu FM, Zhou KY, et al. EGCG decreases the expression of HIF-1alpha and VEGF and cell growth in MCF-7 breast cancer cells. Journal of BUON : official journal of the Balkan Union of Oncology. 2014; 19: 435-9.

152. Chung SS, Vadgama JV. Curcumin and epigallocatechin gallate inhibit the cancer stem cell phenotype via down-regulation of STAT3-NFKB signaling. Anticancer research. 2015; 35: 39-46.

153. Liao G, Gao B, Gao Y, Yang X, Cheng X, Ou Y. Phycocyanin Inhibits Tumorigenic Potential of Pancreatic Cancer Cells: Role of Apoptosis and Autophagy. Sci Rep. 2016; 6: 34564-.

154. Nishanth RP, Ramakrishna BS, Jyotsna RG, Roy KR, Reddy GV, Reddy PK, et al. C-Phycocyanin inhibits MDR1 through reactive oxygen species and cyclooxygenase-2 mediated pathways in human hepatocellular carcinoma cell line. European Journal of Pharmacology. 2010; 649: 74-83.

155. Kuttikrishnan S, Siveen KS, Prabhu KS, Khan AQ, Ahmed EI, Akhtar S, et al. Curcumin Induces Apoptotic Cell Death via Inhibition of PI3-Kinase/AKT Pathway in B-Precursor Acute Lymphoblastic Leukemia. Front Oncol. 2019; 9: 484-.

156. Baharuddin P, Satar N, Fakiruddin KS, Zakaria N, Lim MN, Yusoff NM, et al. Curcumin improves the efficacy of cisplatin by targeting cancer stem-like cells through p21 and cyclin D1-mediated tumour cell inhibition in non-small cell lung cancer cell lines. Oncology reports. 2016; 35: 13-25.

157. Fu H, Wang C, Yang D, Wei Z, Xu J, Hu Z, et al. Curcumin regulates proliferation, autophagy, and apoptosis in gastric cancer cells by affecting PI3K and P53 signaling. Journal of Cellular Physiology. 2018; 233: 4634-42.

158. Das I, Das S, Saha T. Saffron suppresses oxidative stress in DMBA-induced skin carcinoma: A histopathological study. Acta Histochemica. 2010; 112: 317-27.

159. Jin $W$, Zhang $Y$, Xue $Y$, Han $X$, Zhang $X$, Ma Z, et al. Crocin attenuates isoprenaline-induced myocardial fibrosis by targeting TLR4/NF-KB signaling: connecting oxidative stress, inflammation, and apoptosis. Naunyn-Schmiedeberg's Archives of Pharmacology. 2019.

160. Naeimi M, Shafiee M, Kermanshahi F, Khorasanchi Z, Khazaei M, Ryzhikov M, et al. Saffron (Crocus sativus) in the treatment of gastrointestinal cancers: Current findings and potential mechanisms of action. Journal of Cellular Biochemistry. 2019; 120: 16330-9. 